\title{
MIŠLJENJE O USTAVNOPRAVNIM PITANJIMA KOJA SE POSTAVLJAJU POVODOM OSPORENIH ODREDABA ZAKONA O NACIONALNIM SAVETIMA \\ - Izneto na javnoj raspravi pred Ustavnim sudom 2. jula 2013. godine -
}

\section{KonteKST OVLAŠĆENJA NACIONALNIH SAVETA}

Prema Deklaraciji Generalne skupštine UN od 18. decembra 1992. godine o pravima pripadnika etničkih, verskih i jezičkih manjina (br. A/ Rez/47/135): Unapređivanje i zaštita prava etničkih, verskih $i$ jezičkih manjina doprinosi društvenoj i političkoj stabilnosti zemalja u kojima te manjine žive. Zakon o nacionalnim savetima (ZNS) predstavlja veoma značajan korak u pravcu takve stabilnosti, odnosno u pravcu da svi građani - bez obzira na etničku pripadnost - prihvate Srbiju kao svoju državu. Zakon i ideje Zakona nisu odmah prihvatili svi. Bili su protiv Albanci iz okoline Preševa, sa argumentacijom da je to izdaja albanskih interesa. Na kraju je ipak formiran i albanski nacionalni savet. Bili su protiv i neki radikalni političari iz redova mađarske nacionalne manjine sa argumentom da je to zaštita srpskih interesa i protiv mađarskih interesa; oni su i bojkotovali izbore, ali se pokazalo da su njihov uticaj i podrška među biračima marginalni. Bilo je i pripadnika nekih drugih manjina, koji nisu bili zadovoljni Zakonom o nacionalnim savetima i situacijom koja je tim zakonom stvorena.

Pokazalo se i to, koji je osnovni razlog iza ovih protivljenja. ZNS istina daje pripadnicima manjina značajna kulturna prava - koja su neki pripadnici manjina smatrali nedovoljno širokim, a neki pripadnici većine preširokim. No ta prava se vezuju za kulturu, a ne za teritoriju. Kulturna samouprava daje značajna prava pripadnicima nacionalnih manjina, ali istovremeno čini jasnim da su to prava za održavanje i negovanje različitih

Redovni profesor na Centralnoevropskom univerzitetu u Budimpešti i profesor emeritus na Pravnom fakultetu Emory univerziteta u Atlanti, SAD e-mail: varadyt@ceu.hu 
kultura na jedinstvenoj teritoriji, unutar jedne iste zemlje. Neki radikalni manjinski političari - u Srbiji, pa i u nekim drugim zemljama - nastoje da budu heroji na taj način što ne prihvataju zemlju u kojoj žive kao svoju. Ovaj stav postaje marginalizovan i obesmišljen ako se omogući da Mađari, Rumuni, Slovaci, Hrvati, Rusini, Bugari i drugi mogu da upravljaju svojom kulturom u Srbiji, kao građani Srbije.

ZNS je dobio i značajna međunarodna priznanja jer se zasniva na savremenom principu da je pravo na različitost u domenu kulture (kao i u domenu religije) elemenat prava na jednakost. U godišnjim izveštajima Evropske komisije (Progress Report ili Analytical Report) nakon donošenja ZNS-a redovno se daje pozitivna ocena ZNS-a - ponekad uz opasku da treba i dalje raditi na realizaciji. Pozitivna ocena ZNS-a je postala važan oslonac evropskih procena stanja manjinskih prava. U Analytical Report Evropske komisije od 12. oktobra 2011, koja se bavi zahtevom Srbije za prijem u EU, pozitivna ocena stanja zaštite manjinskih prava počinje sledećom rečenicom: Ustav garantuje pripadnicima nacionalnih manjina posebna prava pored prava koja se garantuju svim gradanima, te uvodi manjinske nacionalne savete kao ustavnu kategoriju. (str. 32) Da navedem još jedan primer, Misija OEBS-a u Srbiji je izdala poseban priručnik za nacionalne savete nacionalnih manjina, a u uvodu tog priručnika kaže se da Misija nastoji da podrži savete kao predstavnička tela manjina u ostvarivanju njihovih nadležnosti.

Od posebnog je značaja da je Evropski parlament u brojnim rezolucijama i deklaracijama (kao što su rezolucije i deklaracije u vezi sa evropskom integracijom Srbije) istakao važnost nacionalnih saveta. Ove rezolucije i deklaracije pozdravljaju demokratski izabrane nacionalne savete, ističu „progresivni sadržaj” Zakona o nacionalnim savetima i u više navrata ukazuju na to da je neophodna puna implementacija zakonom postavljenih nadležnosti nacionalnih saveta. ${ }^{1}$

1 Naveo bih sedam relevantnih rezolucija i deklaracija Evropskog parlamenta. Podvučeni su delovi teksta koji se odnose na nacionalne savete.

Relations between the European Union and Serbia 2007/2126(INI)

36. Takes notes of the establishment of an Agency for Human and Minority Rights, directly under the Prime Minister, replacing the former State Union Ministry for Human and Minority Rights; calls on the Prime Minister to pursue a coherent and active minority policy and to ensure that human and minority rights are a priority on the Government's agenda; welcomes the fact that the new Serbian Constitution gives a constitutional basis to the National Councils of ethnic minorities and calls for the adoption of new legislation to provide better regulation for the status, work, and election of these Councils; looks forward to such legislation providing an improved legal framework for the protection of minority rights and the integration of all national minorities into state structures;

\section{Resolution on the European integration process of Serbia} 2010/2980(RSP)

25. Welcomes the establishment of a majority of the national minority councils, allowing them to take decisions in the fields of education, culture, use of minority lan- 
Tibor Várady, Mišljenje o ustavnopravnim pitanjima povodom osporenih odredaba ZNS

Pravo na različitost je značajno ne samo za manjine u Srbiji već i za Srbe van granica Srbije. To je, primera radi, logična osnova na kojoj se

guages and public information; notes the importance of the full implementation of the competencies of these minority self-governing bodies and the necessity of adequate budgetary subsidies guaranteed by the Law on National Minority Councils; notes the complaints about the irregularities in the preparation process and the legal requirements for the establishment of the councils, as well as the complaints about the violation of the guaranteed competencies of national councils by some ministries and local municipalities, and calls on the authorities to respond to them; raises concerns regarding the setting-up of the Bosniak national council and calls for a swift conclusion of the process in compliance with the rules, permitting legitimate representation of the Bosniaks in the council; is concerned about increasing tensions in Sandžak, as manifested inter alia by recent violent incidents, and strongly calls for political disputes to be resolved through dialogue within the framework of democratic institutions;

\section{Resolution on the European integration process of Serbia} 2011/2886(RSP)

28. Welcomes the functioning of the democratically elected national minority councils, which represent national minorities in the fields of education, culture, media and official language use; notes, however, the importance of the full implementation of the competencies of these minority self-governing bodies and the necessity of adequate budgetary subsidies guaranteed by the Law on National Minority Councils; notes with concern the complaints about the irregularities in the preparation process and the legal requirements for the establishment of the councils, as well as the complaints about the violation of the guaranteed competencies of national councils by some ministries and local municipalities, and calls on the authorities to respond to them; welcomes those decisions of the Serbian Administrative Court which have upheld the cases brought by the National Council of the Hungarian National Minority arising from the violation of the competencies of the National Council by local authorities;

\section{Resolution on the 2012 progress report on Serbia}

\section{2/2868(RSP)}

41. Welcomes the fact that the legislative framework with regard to national, ethnic and cultural minorities in Serbia is in place; stresses, however, that more efforts are needed to ensure its effective implementation throughout Serbia; calls on the authorities to address known shortcomings, particularly with regard to the fair representation of minorities in the public administration, judiciary and police; insists that more consistent and prompt measures are necessary to ensure unrestricted access to quality education in minority languages at state and provincial level, since this is necessary to preserve ethnic and cultural identity, and in particular to provide all necessary textbooks and other educational materials; calls on the authorities to ensure that all necessary budgetary subsidies are provided to Minority Councils; calls on the Commission to continue to closely monitor Serbia's efforts in this area;

Joint Declaration and recommendations of the 5th EP-Serbia Inter-parliamentary meeting 9. Welcomed the democratic election of national councils of national minorities as a forward looking step towards the effective protection of these minorities, noted however the continuous failure to establish the Bosniak National Council and that non-observance of the legally guaranteed competencies of the councils by some local authorities raise concerns; underlined that the implementation of minority rights by the executive is as important as the legislative Act itself;

Joint Statement adopted at the 6th EP-Serbia Inter-parliamentary Meeting, Belgrade, 27-28 September 2012 
zasniva prenošenje osnivačkih prava nad srpskim školama u Mađarskoj sa državnih institucija na srpsku samoupravu. Iz te logike sledi, takođe, da pitanje pisma (latinice i ćirilice) u Hrvatskoj ne bi smelo da zavisi samo od volje većine svih građana već treba priznati posebno pravo srpske manjine da sačuva svoje pismo. Takva ovlašćenja se ne mogu shvatiti kao kršenje jednakosti građana, već kao postulat stvarne jednakosti.

Zakon se primenjuje već više od tri godine. U toku primene, bilo je, naravno, nesporazuma i sporova, ali je sve to rešavano pred nadležnim ministarstvima i sudovima u Srbiji. Ni u jednom slučaju nije bilo čak ni obraćanja Strazburu (što, inače, ne bi bilo po sebi neprihvatljivo), sve je rešavano unutar pravnog sistema Srbije.

Ako je u jednoj državi uporedo postojanje više kultura normalnost, onda je normalno i to da pripadnici više kultura prihvataju tu državu kao svoju.

\section{PITANJE PRENOSA OSNIVAČKIH PRAVA}

Prenos osnivačkih prava je osporen povodom više odredaba Zakona o nacionalnim savetima (ZNS), a posebno povodom odredaba člana 11 . stav 3, člana 19. stav 2. i člana 24.

U vezi sa članom 11. ZNS, postavlja se pitanje da li je prenos osnivačkih prava u skladu sa članom 79. Ustava. Smatram da je prenos osnivačkih prava jasno u funkciji ostvarivanja člana 75. Ustava - i ne protivreči članu 79.

Prema članu 75. Ustava Srbije, nacionalne manjine imaju pravo na samoupravu u oblasti kulture, obrazovanja, obaveštavanja i službene upotrebe jezika i pisma. Radi ostvarenja ove samouprave, nacionalne manjine mogu da biraju nacionalne savete. Ova se samouprava ostvaruje u skladu sa zakonom. Prema tome, ustavna je obaveza zakonodavca da stvori okvire samouprave u navedenim oblastima. Osnivačka prava su ključni

4. Recommended to local authorities to implement the legally guaranteed competencies of national councils; underlined that the implementation of minority rights by the executive is as important as the legislative act itself;

Joint Statement adopted at the 7th EP-Serbia Inter-parliamentary meeting, Brussels, 18-19 March 2013

14. Welcomed the protection of national, ethnic and cultural minorities in the legislative framework of Serbia, particularly in relation to the fair representation of minorities in public administration, the judiciary and the police forces; underlined the importance of the Law on national councils of national minorities, its progressive content and the necessity for its wide implementation and application with full respect to their competencies; insisted that consistent and prompt measures ought to be taken to ensure an unrestricted access to a quality education in minority languages on both a state and provincial level; suggested that procedural transparency and open communication towards the citizens in the media will ease tensions and promote reconciliation between the different nationalities and ethnicities in the region; 
elemenat samouprave. Član 18. Ustava Srbije govori o neposrednoj primeni Ustavom zajemčenih ljudskih i manjinskih prava i, između ostalog, predviđa: Zakonom se može propisati način ostvarivanja ovih prava samo ako je to Ustavom izricito predvideno, ili ako je to neophodno za ostvarenje pojedinog prava zbog njegove prirode, pri čemu zakon ni u kom slučaju ne sme da utiče na suštinu zajemčenog prava.

U članu 75. Ustav izričito predviđa da se pravo na samoupravu u oblasti kulture, obrazovanja, obaveštavanja i službene upotrebe jezika i pisma ostvaruje u skladu sa zakonom. Taj zakon je ZNS. Očigledno je potrebno i da se propiše način ostvarivanja ovih prava. Ne može biti sumnje da je vršenje osnivačkih prava upravo način ostvarivanja samouprave, i da to nije protivno suštini zajemčenog prava, već je neophodno da bi se mogla ostvariti suština zajemčenog prava na samoupravu.

Treba primetiti da se u vezi sa članom 11. zapravo ne osporava pravo nacionalnih saveta da budu osnivači ustanova u oblasti vaspitanja i obrazovanja, već se osporava prenošenje tih prava na nacionalne savete od strane republike, pokrajine ili lokalne samouprave. Jasno je, međutim, da je prenošenje neophodno za ostvarenje tih zajemčenih prava. Slične situacije nalazimo i u uporednom pravu. U Mađarskoj, na primer osnivačka prava srpske predškolske ustanove, srpske osnovne škole, srpske gimnazije, kao i đačkog doma u Budimpešti, preneta su sa mađarskih državnih institucija na Srpsku samoupravu (s tim da - kao što je to slučaj i u Srbiji - finansiranje i dalje ostaje odgovornost države). Ne bi imalo nikakvog smisla da Srpska samouprava osnuje nove paralelne srpske škole u Budimpešti. Mnogo je smislenije da se prenesu osnivačka prava. U Srbiji, razne manjinske kulture ne počinju donošenjem ZNS-a. Ustanove u oblasti vaspitanja i obrazovanja koje deluju (i) na jezicima manjina, kao i ustanove u oblasti kulture i obaveštavanja postojale su i pre donošenja ZNS-a. Bilo bi ne samo neracionalno, već praktično i nemoguće stvoriti svuda nove ustanove pored postojećih čiji su osnivači republika, pokrajina ili lokalne samouprave. $\mathrm{Za}$ to nema ni potrebe ni kapaciteta. Neophodno je, dakle, transformisati zatečeno stanje, da bi se ostvarili principi Ustava. To je jedan od razloga donošenja ZNS-a. Ako se ne bi mogla preneti osnivačka prava, ostalo bi bez sadržine pravo na samoupravu onih nacionalnih manjina koje su i pre donošenja ZNS-a imale škole na svom jeziku, jer nema ni đaka ni para da se stvori jedan novi paralelni sistem obrazovnih ustanova. Logično je, dakle, da se ne mogu ostvariti ustavni princip i norma iz člana 75. ako se ne predviđa opcija prenošenja osnivačkih prava. Omogućavanje preuzimanja osnivačkih prava je nedvosmisleno u funkciji ostvarenja člana 75. Ustava.

Postavlja se i pitanje da li ogradu predstavlja član 79. Ustava. Što se tiče člana 79 , mislim, pre svega, da bi bilo pogrešno shvatiti taj član kao 
jedno ograničenje manjinskih prava, kada je smisao člana 79. garantovanje manjinskih prava. No čak i ako bi se tim članom postavila neka ograda, ona nije pređena. Član 79. Ustava Srbije, po kojem pripadnici nacionalnih manjina imaju pravo na školovanje na svom jeziku u državnim ustanovama i ustanovama autonomnih pokrajina, nije ničim povređen ako se nacionalni saveti javljaju kao osnivači vaspitnoobrazovnih ustanova. Vaspitnoobrazovne ustanove čiji su osnivači nacionalni saveti (pa i one na kojima su osnivačka prava u celini ili delimično preneta na nacionalne savete), ostaju, naravno, u okvirima pravnog sistema i školskog sistema Srbije. Pre svega, član 79. ne kaže da pravo na školovanje u državnim ustanovama isključuje svako drugo pravo na školovanje. Što je još važnije, država i nakon prenošenja osnivačkih prava ostaje odgovorna za obezbeđivanje prava na obrazovanje na maternjem jeziku, a takve ustanove ostaju deo mreže osnovnih i srednjih škola Srbije. Valja dodati i to da je u ogromnoj većini slučajeva reč o delimičnom prenosu osnivačkih prava, dakle ustanove ne gube svojstvo državne ustanove, one i formalno ostaju ustanove čija osnivačka prava (makar delom) vrše Republika ili Autonomna pokrajina Vojvodina. I konačno, potpuno bi se obesmislilo ustavno pravo na samoupravu ako se osnivačka prava (koja su do donošenja ZNS-a pripadala Republici ili Pokrajini) ne bi mogla ni delimično preneti na organe koji po Ustavu ostvaruju samoupravu u oblasti obrazovanja, vaspitanja, kulture i obaveštavanja.

Isto se odnosi i na član 19. stav 2. ZNS. Ako se Ustavom uspostavlja pravo nacionalnih manjina na samoupravu u oblasti obaveštavanja putem nacionalnih saveta, onda je ustavna obaveza da se to i omogući. Zakon može (i treba), shodno članu 18. stav 2. Ustava da propiše način ostvarivanja ovog prava - a prenošenje osnivačkih prava je očigledno način ostvarivanja prava iz člana 75. (Zapravo ostvarivanje tih prava je praktično nemoguće bez potpunog ili delimičnog prenosa osnivačkih prava.) Pored toga, sve norme kojima se reguliše sloboda štampe odnose se i na medije čija osnivačka prava vrše nacionalni saveti (kao što se odnose i na privatne medije.)

Sve to važi i u pogledu člana 24. ZNS, koji govori o obavezi prenosa (mada ne i potpunog prenosa) osnivačkih prava kada je reč o ustanovama koje deluju isključivo na jeziku određene manjine.

Postavljeno je i pitanje može li prenos da „zavisi isključivo od volje nacionalnog saveta". Prenos osnivačkih prava ne zavisi isključivo od volje nacionalnog saveta, već od volje zakonodavca, odnosno Skupštine Republike Srbije. Zakonodavac je tako odlučio na osnovu člana 75. Ustava. Ustav Srbije je ustanovio pravo na samoupravu nacionalnih manjina $\mathrm{u}$ oblasti kulture, obrazovanja i obaveštavanja, a ZNS je to pravo delimično 
ostvario putem mogućnosti prenošenja osnivačkih prava na samoupravu nacionalnih manjina u tim oblastima. Osnivačka prava i prenošenje osnivačkih prava su logičan način ispunjenja obaveze države u skladu sa čl. 75 . i 79. Ustava. Nijedna norma Ustava ne ograničava zakonodavca da li će to prenošenje postulirati kao mogućnost ili kao zakonski uslovljenu obavezu u slučaju zahteva zakonom ovlašćenog nacionalnog saveta. Zakonodavac je to postavio kao obavezu kada je reč o ustanovama u kojima se nastava, odnosno informisanje ostvaruje isključivo na manjinskom jeziku (ili čija je osnovna delatnost očuvanje manjinske kulture) - ali je to samo mogućnost (a ne obaveza) ako je reč o ustanovama koje nisu isključivo ustanove manjinske kulture. No čak i kada je reč o ustanovama koje funkcionišu isključivo na manjinskom jeziku, ne postoji obaveza potpunog prenošenja osnivačkih prava, moguće je i delimično prenošenje. To ostaje u granicama razložne razrade ustavnopravne obaveze obezbeđivanja samouprave, odnosno „propisivanja načina ostvarivanja tih prava”.

\section{DRUgi NAČINI OSTVARIVANJA SAMOUPRAVE U OBLASTI}

\section{OBRAZOVANJA}

Postavlja se pitanje ustavnosti određenih odredaba čl. 12, 13, 14. i 15. ZNS u kojima se predviđaju određene nadležnosti nacionalnih saveta $\mathrm{u}$ oblasti obrazovanja. Te nadležnosti ne dostižu nivo odlučivanja. Reč je o učešću u procesu odlučivanja, a u najvećem broju slučajeva o vrlo ograničenom učešću, koje se svodi na davanje mišljenja koje nije obavezno.

Predlagači u više navrata postavljaju pitanje da li se time povređuje princip jedinstva pravnog poretka. (Recimo, time što se traži prethodna saglasnost nacionalnih saveta kada je reč o predlaganju udžbenika čiji sadržaj izražava posebnosti nacionalne manjine.) Mislim da treba zastati kod pitanja percepcije jedinstva pravnog poretka. Čini mi se da je ovde reč o jednom nesporazumu.

Jedinstvo pravnog poretka ne može biti povređeno time što se standardni mehanizmi (recimo, kod odobravanja udžbenika) dopunjuju posebnim instrumentima kada je reč o manjinskoj kulturi. Pozicija člana 75 - pa i brojnih drugih odredaba Ustava - logična je. U svim državama kultura većinskog naroda se prirodno štiti standardnim mehanizmima države. Pored toga, standardni mehanizmi države pružaju jednaku zaštitu svim građanima (bez obzira na etničku pripadnost) u svim pitanjima $u$ kojima su građani jednaki. Ti standardni mehanizmi se, međutim, nužno dopunjuju tamo gde su građani različiti, i gde se pravo na jednakost može ostvariti samo kroz pravo na različitost. Srbi u Hrvatskoj su jednaki ako 
imaju sva građanska prava kao i Hrvati. Ali ako je reč o pismu, Srbi u Hrvatskoj nisu jednaki ako imaju isto pravo da uče latinicu kao i Hrvati. Posebna pravila i postupci u pogledu pisma, škola ili udžbenika različitih grupa građana ne remete jedinstvo pravnog poretka. U domenu kulture, pravo na različitost se najefikasnije ostvaruje kroz samoupravu u domenu kulture. Pravo na različitost je neophodan elemenat stvarne jednakosti. U svom čuvenom mišljenju u South-West Africa Cases $^{2}$ sudija Međunarodnog suda pravde Tanaka ističe da je prava sadržina principa jednakosti u tome da se ono što je jednako tretira jednako, a ono što je različito tretira različito. Tanaka dodaje da nije samo dozvoljeno već je i neophodno da se različite stvari tretiraju u skladu sa svojom različitošću. Tako se zapravo stvara jednakost.

Jednakost vodi ka pravednosti samo ako se oslanjamo na relevantan zajednički imenitelj. Najčešće je taj zajednički imenitelj prosto svojstvo građana. Svi građani treba da budu jednaki pred zakonom. Ako je reč, recimo, o zdravlju, jednakost postoji ako svi građani imaju jednak pristup istim zdravstvenim ustanovama. Ali kada je reč, recimo, o religiji, relevantni zajednički imenitelj nije svojstvo građana, već pripadnost jednoj religiji. Nema jednakosti ako svi građani jedne države imaju jednak pristup istoj crkvi. Jednakost postoji ako svako može da ide u svoju crkvu. Isto tako, nije jednakost ako svi građani mogu da idu u škole na istom jeziku. Ovom logikom stvarne jednakosti su rukovođeni i brojni međunarodni dokumenti, među kojima bih pomenuo Deklaraciju UNESCO-a o rasi i rasnoj predrasudi iz 1978. g. u kojoj se naglašava „pravo svih pojedinaca i grupa da budu različiti." ${ }^{3}$ Okvirna konvencija Saveta Evrope za zaštitu nacionalnih manjina koju smo ratifikovali (Sl. list SRJ - Međunarodni ugovori, br. 6/98) takođe govori u članu 4. stav 2. o merama za obezbeđivanje „pune i stvarne jednakosti pripadnika nacionalnih manjina”, ističući da se „u tom pogledu mora voditi računa o specifičnim uslovima pripadnika nacionalnih manjina".

Ako se ozbiljno shvati ustavni princip samouprave nacionalnih manjina u oblasti obrazovanja, onda to treba ostvariti kroz neke instrumente. Ti instrumenti se ne bi smeli percipirati kao elemenat narušavanja jedinstva pravnog poretka, već kao integralni deo obrazovnog i pravnog sistema naše države.

Pominje se i plaćanje poreza. Ako plaćanje poreza pruža neku osnovu za učešće u procesu odlučivanja u pitanjima kulture i obrazovanja, logično je da se manjinama (koje takođe plaćaju porez) pruža osnova za učešće u upravljanju svojom kulturom i obrazovanjem na svom jeziku.

2 I.C.J. South-West Africa Cases (Second Phase) 1966, Dissenting Opinion of Judge Tanaka I.C.J. Reports, 1966, 6, pp. 250-324.

3 Vidi čl. 1. i 5. UNESCO Declaration on Race and Racial Prejudice, 1978. 
Član 12. ZNS postavlja dosta skromna prava u pogledu učešća u upravljanju u obrazovnim ustanovama u kojima se vaspitno-obrazovni rad izvodi i na jeziku nacionalnih manjina. To je jasno u skladu sa normama člana 75. Ustava, jer je očigledno reč o učešću u odlučivanju o pitanjima vezanim za kulturu i obrazovanje manjina. To se odnosi i na član 14 . ZNS koji govori o predlogu nadležnom ministru za davanje odobrenja za korišćenje udžbenika čiji sadržaj izražava posebnosti nacionalne manjine.

Kada je reč o ustanovama učeničkog i studentskog standarda, ovde nije neposredno reč o izvođenju nastave na jeziku većine ili manjina, ali je i dalje reč o obrazovanju. Ustav daje pravo na samoupravu, tj. na odlučivanje u obrazovanju, a ne samo u školama, odnosno u nastavi. Član 2. Zakona o učeničkom i studentskom standardu neposredno potvrđuje da učenički i studentski standard spada u oblast obrazovanja (dakle predstavlja deo oblasti u kojoj se ostvaruje pravo na samoupravu u skladu sa članom 75. Ustava). (Prema članu 2: Učenički i studentski standard, u smislu ovog zakona, jeste organizovana delatnost kojom se u oblasti obrazovanja $i$ vaspitanja obezbeduju dodatni uslovi za dostupnije, efikasnije i kvalitetnije obrazovanje i vaspitanje učenika i studenata.)

Kada je reč o odredbi koja pravo učešća u odlučivanju proširuje i na nacionalne savete čiji jezik nije u službenoj upotrebi ni u jednoj jedinici lokalne samouprave (već je osnova za učešće to da neka manjina predstavlja 1\% ukupnog stanovništva na teritoriji date lokalne samouprave) tu zaista dolazimo do granica ustavnih prava učešća u odlučivanju, te bi ova odredba mogla opstati samo sa oslonom na član 21. Ustava.

Što se tiče ustavnosti člana 13. stav 3. (davanje mišljenja u vezi sa nastavnim programima srpskog kao nematernjeg jezika), trebalo bi reći sledeće. U Srbiji, srpski jezik jeste deo nastave u slovačkim, rumunskim, mađarskim, ili drugim manjinskim školama - i tako i treba da bude. Nastava srpskog kao nematernjeg jezika je značajan elemenat nastave u školama nacionalnih manjina. Sistem obrazovanja na manjinskom jeziku logično uključuje učenje jezika većine. Dakle to ostaje u okvirima člana 75. Ustava. Ako se srpski jezik ne izučava kao maternji jezik, već kao jezik sredine, to naravno opredeljuje pedagoški pristup. Logično je i korisno da nacionalni saveti pojedinih nacionalnih manjina daju mišljenje Nacionalnom prosvetnom savetu o tome kako bi se najefikasnije mogao izučavati srpski jezik u manjinskim školama. Ova mišljenja ne obavezuju Nacionalni prosvetni savet, ali mogu biti od koristi.

Pomenuo bih još i to da samouprava po pravilu znači odlučivanje. Osporene odredbe se tiču davanja mišljenja i predloga, što nije više, nego manje od odlučivanja. Reč je, dakle, o oblicima ograničenog učešća u odlučivanju. Bilo je dosta kritika ZNS-a od strane manjinskih organizacija 
da mišljenja i predlozi ne dostižu samoupravu garantovanu Ustavom. U mnogim osporenim odredbama reč je o davanju (neobaveznog) mišljenja, čime se zaista jedva dostiže prag učešća u odlučivanju.

\section{UČEŠĆE U ODLUČIVANJU KOD RADIODIFUZNIH USTANOVA (ČLAN 20. ZNS)}

I ovde je reč u suštini o istom pitanju kao i kod učešća u odlučivanju $\mathrm{u}$ oblasti obrazovanja. Prava nacionalnih manjina u ovom domenu nisu neka posebno „veća” prava, kao što nije neko posebno veće pravo da u Srbiji pored naziva "Subotica” stoji i "Szabadka” - ili da u Mađarskoj pored naziva "Szentendre” stoji i „Sentandreja”. Reč je o pravu na jednakost onih koji su različiti po svom jeziku i kulturi. Ponovio bih da kada je reč o jezicima i kulturi, većinski mehanizam ne štiti automatski i prava manjina. Zbog toga je potrebno obezbediti manjinama posebna prava za učešće u odlučivanju i kada je reč o obaveštavanju na jezicima manjina, pa i kada je reč o radiodifuznim ustanovama. U skladu sa Ustavom, mišljenja i predlozi legitimnih predstavnika manjina postaju deo opšteg zakonskog mehanizma stupanja u javne službe koje uključuju rad i na jezicima manjina.

Treba reći i to da bez ovih ograničenih ovlašćenja (pravo na davanje mišljenja ili predloga) bilo bi praktično negirano ustavno pravo manjina na samoupravu u jednoj značajnoj oblasti obaveštavanja.

\section{Posledice Nepoštovanja ZAKONA (ČLAN 23. ZNS)}

Logično je da nepoštovanje zakona (bez obzira da li je reč o pojedin$\mathrm{cu}$, pravnom licu ili državnom organu) povlači za sobom određene sankcije. Ovde je reč o tome - može li zakonodavac da propiše da su ništavi pojedinačni pravni akti ako pri njihovom donošenju (suprotno zakonu) nije zatražen predlog ili mišljenje nacionalnog saveta. Zakonodavac je slobodan da propiše sankcije ako time ne prekoračuje neka ustavna ograničenja (koja su najizrazitija u pogledu krivičnih sankcija). U ovom slučaju predlagač se ne poziva ni na jednu konkretnu ustavnu odredbu koja bi postavila ograničenje u pogledu propisivanja sankcije - niti postoji takva ustavna odredba. Obaveza izvršne vlasti da se pridržava zakona ne može se shvatiti kao neustavno „ograničenje izvršne vlasti [...] u odlučivanju u upravnom postupku". Zakonodavac ima prirodno slobodu da propiše sankcije za nepoštovanje zakona.

Što se tiče roka od 30 dana za davanje predloga ili mišljenja, mislim da bi se, naravno, moglo govoriti o tome da li je taj rok najcelishodniji. 
Iskustva iz prakse bi možda mogla da navedu zakonodavca da postavi pitanje da li je celishodniji ovaj ili neki drugi rok. No to nije pitanje ustavnosti, već stručne ocene zakonodavca u pogledu adekvatne dužine roka.

\section{Pokretanje Postupaka, IniCijative, Mišluenja (ČL. 10, 25. I 26. ZNS)}

U vezi sa osporenim stavovima ovih članova hteo bih da dam samo nekoliko kratkih opaski.

Mislim da predlagači daju preširoko tumačenje sadržini ovih ovlašćenja. Učešće u pripremi propisa, predlaganje izmena i dopuna, predlaganje propisa i mera, mišljenja i inicijative ne mogu da ograniče državne organe u tome kakve će propise ili odluke doneti, niti je reč o „mešanju nacionalnog saveta u vršenje zakonodavne vlasti”. Reč je o tome da se zakonodavac (ili drugi nosilac vlasti) konsultuje sa nacionalnim savetima pri donošenju propisa koji se tiču nacionalne manjine. Ničim nije nagovešteno da bi zakonodavac (ili drugi nosilac vlasti) bio na bilo koji način vezan predlozima, inicijativama ili mišljenjima nacionalnog saveta.

Teško je negirati svrsishodnost ovakvih konsultacija. Široka je praksa kako u Srbiji, tako i u drugim državama, da razni zainteresovani subjekti (ne samo nacionalne manjine) učestvuju u pripremi raznih propisa, da daju predloge i mišljenja. To potvrđuju i naši bilateralni sporazumi. Prema članu 7. bilateralnog ugovora sa Rumunijom (Sl. list SCG - Međunarodni ugovori, br. 14/04): Pripadnici nacionalnih manjina imaju pravo da, u skladu sa nacionalnim zakonodavstvom, učestvuju u odlučivanju koje se odnosi na pitanja koja su na državnom, regionalnom i lokalnom nivou značajna za nacionalne manjine. Neki naši bilateralni sporazumi koriste i nešto jače formulacije, govoreći o „delotvornom” učešću nacionalnih manjina u donošenju odluka. Na primer, prema članu 8. bilateralnog ugovora sa Makedonijom (Sl. list SCG - Međunarodni ugovori, br. 6/05): Ugovorne strane će omogućiti delotvorno učešće manjina u donošenju odluka koje se odnose na prava i položaj manjina na lokalnom, regionalnom i državnom nivou [...].

U vezi sa članom 137. Ustava, koji govori o mogućnosti poveravanja javnih ovlašćenja zakonom, postavlja se, pre svega, pitanje da li to isključuje svaku drugu mogućnost poveravanja javnih ovlašćenja. U slučaju člana 10. stav 15. ZNS, zakon predviđa da nacionalni savet odlučuje o nekim pitanjima koja bi mu poverila pokrajina ili lokalna samouprava. Bilo bi previše kruto tumačenje ako bi se shvatalo da mogućnost poveravanja zakonom isključuje mogućnost poveravanja na osnovu zakona. Pored toga, odlučivanje o pitanjima koja su poverena aktom autonomne pokrajine 
(član 10. stav 15) jeste jedna moguća realizacija ustavnog prava pokrajina po članu 79. stav 2. Ustava da na osnovu zakona (kao što je ZNS) ustanove dodatna prava pripadnika nacionalnih manjina. U ovom slučaju (kada je reč o pokrajini) nije potrebno neko elastično tumačenje, jer član 79 . stav 2. Ustava ne govori o ustanovljavanju dodatnih prava zakonom, već „na osnovu zakona". (Po Ustavu, pripadnici manjina mogu imati kako individualna, tako i kolektivna prava, što znači da im se mogu i poveriti kako individualna, tako i kolektivna prava.)

Pokretanje postupka pred Ustavim sudom zaista može da bude sporno u smislu člana 168. Ustava, koji navodi subjekte koji mogu da pokrenu postupak za ocenu ustavnosti i zakonitosti. Postavlja se pitanje da li je moguće pokrenuti postupak pred Ustavnim sudom koji ne bi bio „postupak za ocenu ustavnosti i zakonitosti”. Postupak koji bi bio van onih čiji su pokretači taksativno navedeni u članu 168. Ustava, jeste ustavna žalba - što je i navedeno u "predlogu spornih pitanja”. Prema tome, valja konstatovati da član 168. Ustava navodi subjekte koji mogu da pokrenu postupak za ocenu ustavnosti i zakonitosti, i među tim subjektima nisu navedeni nacionalni saveti - no istovremeno, član 170. Ustava, koji govori o ustavnoj žalbi, ne ograničava krug subjekata koji mogu da podnesu ustavnu žalbu, a posebno ističe da se ustavna žalba može podneti i u slučaju uskraćivanja ljudskih i manjinskih prava. Pored toga, logično je da se legitimnim predstavnicima manjina omogući da pred Ustavnim sudom, Zaštitnikom građana, pokrajinskim ili lokalnim ombudsmanom, ili drugim organima pokreću postupak po pitanjima prava nacionalnih manjina. Valja dodati da Ustav izričito jemči kolektivna prava manjina, a ta prava se mogu štititi samo preko nekog predstavnika - a kod nas su to nacionalni saveti. Logično je, dakle, da se nacionalnim savetima omogući da postupak pokreću i u svoje ime.

\section{Pitanje Osnivanja PRIVREDNih DRUŠtava (ČL. 2. I 10. ZNS)}

Članovi 2. i 10. ZNS predviđaju mogućnost osnivanja privrednih društava samo u oblastima u kojima Ustav garantuje pravo na samoupravu (kultura, obrazovanje, obaveštavanje, službena upotreba jezika i pisma). U Predlogu spornih ustavnopravnih pitanja navodi se da član 75 . Ustava sadrži numerus clausus mogućih oblasti delovanja nacionalnih saveta.

Čak i ako se prihvati stav da član 75. postavlja jedan numerus clausus, reč je o ograničenom broju oblasti u kojima se ostvaruje samouprava, a ne o ograničenom broju institucija ili instrumenata kroz koje se ostvaruje samouprava u tim oblastima. Privredna društva nisu tipični subjek- 
ti ostvarenja samouprave, i najveći broj nacionalnih saveta nije osnovao privredna društva. No osnivanje privrednih društava ne mora da znači iskorak iz oblasti obrazovanja, kulture, ili obaveštavanja. Pored toga, svako pravno i fizičko lice može da osnuje privredno društvo. Kada je reč o nacionalnim savetima, prirodno je da to budu privredna društva samo u oblastima u kojima, u skladu sa Ustavom, deluju nacionalni saveti. Izdavačke kuće su ne retko privredna društva, a njihova delatnost je svakako delatnost u oblasti kulture. Delatnost javnog informisanja se takođe često obavlja preko privrednih društava. Ovakva privredna društva deluju i u oblasti manjinske kulture, na primer izdavač „Kultura” iz Bačkog Petrovca je privredno društvo slovačke manjinske kulture. Prema tome, reč je o odredbama ZNS-a koje imaju ograničen praktičan značaj, ali se ne može reći da je osnivanje takvih društava protivustavno ako se osnivaju unutar oblasti u kojima Ustav garantuje samoupravu nacionalnih manjina.

\section{SARADNJA SA MEĐUNARODNIM I REGIONALNIM ORGANIZACIJAMA (ČLAN 27. ZNS)}

Član 123. Ustava kaže da Vlada „utvrđuje i vodi politiku”. To sigurno uključuje i spoljnu politiku. Ne može se reći, međutim, da je član 27. ZNS u suprotnosti sa članom 123. Ustava. Ničim nije rečeno u članu 27. da nacionalni saveti utvrđuju i vode spoljnu politiku. Nacionalni saveti sasvim sigurno ne vode spoljnu politiku, već to čini Vlada, a pre svega Ministarstvo spoljnih poslova. Međunarodna saradnja je znatno širi pojam od vođenja spoljne politike i ne vezuje se isključivo za državu.

Član 27. predviđa, pre svega, da nacionalni saveti, kao predstavnici nacionalnih manjina u Srbiji, sarađuju sa međunarodnim i regionalnim organizacijama, kao i državnim organima, organizacijama i ustanovama u matičnim državama. Reč je, dakle, o saradnji, a ne o vođenju spoljne politike. To je u skladu sa članom 80. Ustava i u skladu je sa međunarodnim principima. $\mathrm{Na}$ osnovu istih principa i Srbija ima kontakte i sarađuje sa Srbima i njihovim organizacijama van Srbije. Po istoj logici je formirano ranije ministarstvo, a danas Odeljenje za migracionu politiku i dijasporu pri Ministarstvu spoljnih poslova. Ako ovo odeljenje sarađuje sa srpskim samoupravama i drugim organizacijama recimo u Hrvatskoj ili Mađarskoj, iz toga sigurno ne proizilazi da organizacije srpske samouprave $u$ Hrvatskoj ili Mađarskoj vode hrvatsku ili mađarsku spoljnu politiku. Isto tako, ne može se reći da nacionalni saveti vode spoljnu politiku Srbije ako sarađuju sa organima i organizacijama matične države, ili sa međunarodnim i regionalnim organizacijama. 
Što se tiče učešća u pregovorima ili konsultacijama prilikom sklapanja bilateralnih sporazuma (u delu koji se neposredno odnosi na prava nacionalnih manjina), treba reći, pre svega, da se ta odredba nikako ne može tumačiti kao ograničenje prava države da zaključi takav bilateralni sporazum kakav Vlada želi da zaključi. U takve konsultacije se ne retko uključuju i sportske organizacije ili NVO, kada su predmet pregovora pitanja koja se tiču tih organizacija. Treba primetiti i to da ne zavisi od nacionalnog saveta, već od države, da li će predstavnici nacionalnog saveta biti pozvani da učestvuju u delu pregovora, ili će samo biti konsultovani o relevantnim pitanjima. Takve su konsultacije logične i normalne, kao što je logično i normalno učešće nacionalnih manjina u mešovitim međudržavnim telima koja nadziru sprovođenje bilateralnih sporazuma o zaštiti manjina. (U takvim mešovitim telima učestvuju, naravno, i pripadnici srpske manjine iz države sa kojom je zaključen bilateralni sporazum.)

Principe člana 27. potvrđuju i bilateralni sporazumi - koji su, prema članu 16. stav 2. Ustava, deo pravnog poretka Republike Srbije. Primera radi, u članu 11. bilateralnog sporazuma sa Hrvatskom (Sl. list SCG - Međunarodni ugovori, br. 3/05) kaže se:

Strane ugovornice će osigurati manjinama mogućnost svestranih i neposrednih odnosa sa matičnim narodom i njegovim državnim $i$ javnim ustanovama.

\section{Prema članu 13:}

Strane ugovornice će konsultovati predstavnike manjina prilikom priprema medunarodnih ugovora koji su od neposrednog interesa za manjine u odnosu na njihova prava i položaj.

Slične odredbe sadrže i bilateralni ugovori sa Mađarskom, Makedonijom i nekim drugim zemljama. Među više odredaba, naveo bih član 14 . Ugovora sa Makedonijom (Sl. list SCG - Međunarodni ugovori, br. 6/05) u kojem se kaže:

Ugovorne strane ustanovljavaju posebnu međuvladinu Mešovitu komisiju koja prati sprovođenje ovog sporazuma. Ugovorne strane u komisiji delegiraju isti broj predstavnika, a obavezno predstavnike manjina.

Prema članu 16. Ugovora sa Mađarskom (Sl. list SCG - Međunarodni ugovori, br. 14/04), predviđa se formiranje Međuvladine mešovite komisije koja prati sprovođenje sporazuma. U pogledu sastava komisije rečeno je:

Članovi Komisije koji su predstavnici madarske manjine u Srbiji i Crnoj Gori imenovaće se na predlog Nacionalnog saveta mađarske nacionalne manjine u Srbiji i Crnoj Gori, a predstavnici srpske manjine u Mađarskoj na predlog Samouprave Srba u Republici Mađarskoj. 


\section{UPOTREBA IZRAZA „NADLEŽNOST”}

Hteo bih da nešto kažem i o upotrebi pojma „nadležnost”.

Konstatovano je - i to je nesumnjivo - da Ustav koristi reč „nadležnost" u vezi sa ovlašćenjima republike, pokrajine, opština, kao i državnih organa. Predlog spornih ustavnopravnih pitanja to potkrepljuje sa pozivom na čl. 97, 183, 190. i član 189. stav 3. Ustava. Takođe je konstatovano da član 137. stav 2. Ustava koristi izraz „javna ovlašćenja” u kontekstu poveravanja kompetencija ustanovama, preduzećima, organizacijama. To je nesporno, ali iz toga još ne sledi zaključak da se u srpskom pravu ne može govoriti o nadležnosti ustanova ili organizacija.

Nije svako korišćenje određenih termina u Ustavu istovremeno i ustavna definicija tih termina; korišćenjem jednog izraza ne povlače se automatski pojmovne granice. Ako jedan ustav zaista definiše neki izraz, onda je time opredelio pojmovne granice tog izraza unutar određenog pravnog sistema. U našem slučaju, mi nemamo ustavnu definiciju izraza „nadležnost”. Korišćenje jednog izraza može, naravno, da bude indikacija o granicama tog izraza, ali to još nije definicija. Izjednačiti korišćenje izraza sa definisanjem je posebno opasno kod izraza koji imaju veoma široko polje značenja i široku upotrebu. To važi za izraz "nadležnost”, kao što važi, recimo, za izraze „odgovornost”, „funkcija”, „zaštita”, i za mnoge slične izraze. Ustav, naravno, može da povlači granice. Ako se kaže da "zakonodavnu nadležnost” ima samo republika, onda je to granica, druge teritorijalne jedinice ne mogu donositi zakone. Ali time nisu istovremeno i opredeljene i granice svih reči kojima je princip izrečen; nije, recimo, opredeljen domašaj izraza "nadležnost”.

Dodao bih i to da u srpskom jeziku izraz „nadležnost” ima nešto šire polje značenja nego $u$ nekim drugim jezicima. $U$ engleskom postoji više izraza kojima se uobličava taj veoma široki pojam. Pre svega competence, ali ako je reč o nadležnosti sudova, koristi se reč jurisdiction. U francuskom, opet, reč compétence ima slično široko polje značenja kao i srpski izraz „nadležnost”. Izraz compétence koristi i francuski Ustav iz 1958. g. (na primer u čl. 53, 71, 72. i drugim); no razni drugi francuski propisi (kao što je, na primer, Zakon o parničnom postupku) koriste izraz compétence u drugačijim kontekstima. To je zapravo tako i u srpskom pravu. Izraz „nadležnost” pokriva šire značenje od nadležnosti državnih organa i mnogi zakoni - ne samo ZNS - koriste ovaj izraz označavajući nadležnosti različitih ustanova i organizacija.

Dodao bih da nacionalni saveti zapravo i ne spadaju jednosmisleno među „preduzeća, ustanove, organizacije i pojedince” o kojima govori član 137. stav 2. U Predlogu se opravdano konstatuje da su nacionalni saveti 
„specifične organizacije”. Dakle, ostalo bi otvoreno pitanje da li je u pogledu nacionalnih saveta ispravnije koristiti izraz „nadležnost” ili ,javna ovlašćenja" čak i ako bi se zauzelo stanovište da je domašaj tih pojmova zaista ograničen članovima 97, 183, 190. i članom 189. stav 3. - odnosno članom 137. stav 2. No brojni naši zakoni koriste reč „,nadležnost” ne samo kada se radi o nacionalnim savetima već čak i kada je reč o subjektima izričito pomenutim u članu 137. stav 2. Primera radi, Zakon o Srpskoj akademiji nauka i umetnosti iz 2010. godine definiše SANU kao ustanovu, u članu 3. kaže se da je to „samostalna ustanova kojom upravljaju njeni članovi”. Ipak, i taj zakon govori o nadležnosti. Član 24. govori o nadležnosti Skupštine SANU, član 27. govori o nadležnosti Predsedništva SANU, član 34. govori o nadležnosti Upravnog odbora SANU, a član 38. govori o nadležnosti Naučnog veća SANU. Očigledno je da izraz „nadležnost” ima široko polje značenja - i koristi se u našem pravnom sistemu u širokom polju značenja. Zakon o zadužbinama i fondacijama iz 2010. godine govori u članu 37. o „nadležnosti upravnog odbora”. Zakon o privrednim društvima (2011) pominje nadležnosti skupštine (član 329) odnosno izvršnog direktora (član 388) akcionarskog društva. Zakon o arbitraži iz 2006. godine govori o nadležnosti arbitražnih sudova (koji nisu državni organi) u članovima 27-29, i precizira da tu nadležnost stvara volja parničnih stranaka. Pravilnik Spoljnotrgovinske arbitraže pri Privrednoj komori Srbije govori o „nadležnosti” arbitraže i takođe ističe da se ta nadležnost stvara voljom stranaka. Postoje i brojni drugi primeri. Mislim da ne bi doprinelo stabilnosti pravnog poretka Srbije - pa ni ustavnosti - ako bi se u svim tim slučajevima osporila ustavnost korišćenja reči „nadležnost”. Ponovio bih da izraz "nadležnost” ima veoma široko polje značenja. Okolnost da Ustav koristi jedan segment prostora ovog izraza ne bi smelo da vodi da zaključka da je korišćenje drugih segmenata neustavno.

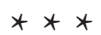

Srbija je zemlja u čijim granicama živi značajan broj pripadnika drugih naroda, kao što je značajan i broj Srba koji žive van granica Srbije. To je istorijska stvarnost, i to je stvarnost sa kojom ulazimo u Evropsku uniju. Naš ustav je uzeo u obzir ovu stvarnost na savremen i napredan način. Omogućio je kolektivna prava i samoupravu manjina u oblastima koje su od značaja za očuvanje njihovog identiteta. Iz toga proizilazi da pravni sistem postaje složeniji, ali je nesumnjivo da je taj složeniji pravni sistem i dalje jedinstveni pravni sistem Srbije. Predsednika Republike biraju jednakim pravom glasa svi građani, bez obzira na nacionalnu pripadnost - i to je logično. No logično je i to da pri izboru uprave jedne manjinske škole 
posebna prava imaju pripadnici te manjine - a isto treba da važi i za srpske škole van granica Srbije.

Zakon o nacionalnim savetima je u funkciji već tri godine, postao je naša društvena realnost. Prava koja se koriste postala su stečena prava, koja se posebno štite Ustavom. Postala je realnost da nacionalne manjine imaju pravo na samoupravu u oblastima utvrđenim Ustavom. Kolektivna prava i samoupravu manjina treba, međutim, i shvatiti i razumeti. To ponekad ne sledi automatski. U mnogim oblastima neke stvari su postale očigledne i razumljive, u drugim oblastima još nisu. Ponekad se nedovoljno shvata da škole i kulturne ustanove manjina nisu neko tuđe telo, one su deo Srbije. Čini mi se da nedovoljno razumevanje te normalnosti dovodi i do postavljanja nekih pitanja, koja se ne postavljaju u situacijama koje su u suštini identične, ali spadaju u oblasti koje su već odavno dobro poznate. Postavlja se, na primer, pitanje, mogu li nacionalni saveti da imaju nadležnosti, a smatra se prirodnim (što i jeste prirodno) da akademija nauka, advokatske komore, arbitraža, akcionarska društva ili zadužbine imaju nadležnosti. Postavlja se pitanje da li predstavlja „ograničenje upravne vlasti” ako se predviđaju sankcije za slučaj kršenja nekih odredaba ZNS-a, a ne postavlja se pitanje mogu li se inače postaviti sankcije u slučaju nepoštovanja zakona. Postavlja se pitanje prenosa osnivačkih prava, kao i raznih oblika učešća u odlučivanju, iako je jasno da bez toga nije moguće ostvariti ustavno pravo na samoupravu. Zatim, ako se recimo Nacionalnom savetu Roma daje pravo na inicijative i izražavanje mišljenja u vezi sa pravnim propisima koji se tiču Roma, to se ne bi smelo shvatiti kao „mešanje [Nacionalnog saveta Roma] u vršenje zakonodavne vlasti”. Inicijative i mišljenja ne sprečavaju zakonodavca da donese zakon kakav želi, ali pomažu da se problematika kompleksnije sagleda. Istovremeno, to je način da se Romi (kao i druge manjine) uključe i kao kolektivitet u pravni sistem Srbije i srpsko društvo - društvo u kojem imaju pravo da sačuvaju svoj kulturni identitet.

Mislim da je Ustavni sud pred izuzetno važnim zadatkom - i čast mi je što sam mogao da učestvujem u ovoj raspravi.

Dostavljeno Redakciji: 26. oktobra 2013. god.

Prihvaćeno za objavljivanje: 18. novembra 2013. god. 